\title{
Programmable Logic Controller (PLC) Protected Transformer Banking Trainer Kit for Electrical Engineering Education
}

\author{
Anthony M. Minoza, Blondie T. Sanchez, and Jayson C. Loreto
}

\begin{abstract}
This research will bridge the gap between theoretical concepts of transformer banking and its actual operation without risking the safety of the students as well as the initiating personnel for the laboratory exercises. In electrical engineering, the concept of transformers is very essential to the success of engineering students in terms of electrical engineering applications. Thus, learning the basic of transformers should be taught properly in universities. However, the danger of dealing with high voltages in a range of 220 Vac and above should be taken seriously. To address this problem, a Programmable Logic Controller (PLC) will be integrated into the system. Programmable Logic Controller (PLC) is an industrial solid-state computer that monitors inputs and outputs and makes logic-based decisions for automated processes or machines. The integration of PLC into the system configuration of any transformer banking served as the protection system. Students will be able to learn on how to configure the four (4) different types of transformer banking, namely, (a) delta-wye; (b) wye-delta; (c) delta-delta; and (d) wye-wye. The interconnection of the system is made possible with the aid of relays. The problem with transformer banking is whenever students misconfigured the connection there is a big chance of damaging the equipment and hurting the user. With this trainer, the equipment is being protected along with the user. The trainer developed in this research will be a good equipment to fully grasp the concept of transformers and best way for the students to expand their knowledge towards electrical engineering.
\end{abstract}

Index Terms-Logic controller, plc, three-phase transformer, trainer kit, transformer banking.

\section{INTRODUCTION}

A transformer is an important component in the electrical engineering power system. A typical transformer consists of coils of wire conductor insulated with paper insulation, which are assembled to the core [1]. In electrical engineering education, understanding the basic concept of transformer banking is very necessary to appreciate and utilize the field of power system to its core. However, transformer banking deals with high voltages, thus, it needs to be handled properly to avoid any accidents.

Transmission and distribution of electrical power are more economical in three phase system than single phase system. There are two ways in having three phase connection. This

Manuscript received June 9, 2019; revised October 13, 2019.

The authors are with the Caraga State University, Cabadbaran City, Philippines (e-mail: anthony.minoza@gmail.com, sanchezbt@yahoo.com, jaysonloreto12@gmail.com). can be done by using a single three phase transformer or by using a bank of three phase transformers. Three single-phase transformers can be connected to form a three-phase transformer bank. For transformers, as a particular case, there are three advantages of using a three-phase transformer instead a of three-phase transformer bank: a) cost reduction, b) mass reduction, and c) reduced space [2]. To address the need in understanding the concept of transformer banking this paper proposed a trainer intended for electrical engineering students in learning the basic concepts of three phase systems using a bank of three single phase transformers. For this trainer, Programmable Logic Controller (PLC) is being integrated for the safety of the students. A typical PLC is a device, which consists of a CPU, input and output interfaces, memory, programming device, and user program [3]. CPU act as the brain of the system which allows the user to put command to achieve the desired functionality. In addition, three phase transformers are effectively three interconnected single phase transformers on a single core in cost, size, and weight [4]. The design of the trainer aims to protect the students from dangerous voltage ratings in connecting the configuration for the various types of transformer banking.

\section{MAterials AND MEthodS}

\section{A. Transformer Configuration}

A three-phase transformer has three sets of primary and secondary windings. The type of interconnection of these windings determines whether the transformers are in star or delta configuration [5].

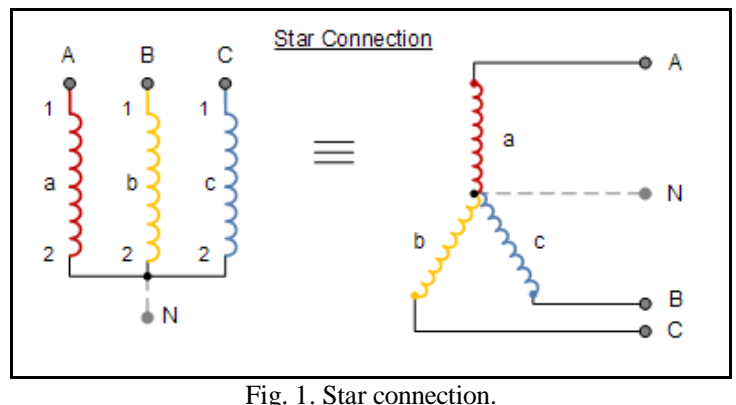

Fig. 1 shows how the transformers are being connected in star configuration. In this configuration, the phase voltage is equal to line voltage divided by square root of three. Also, the phase current is equal to the line current. On the other hand, 
Fig. 2 shows the delta configuration. In this type of configuration, the phase voltage is equal to the line voltage. But, the phase current is equal to line current over the square root of three [6].

(1) $V_{p}=\frac{V_{L}}{\sqrt{3}}$, where $V_{p}=$ Phase voltage, $V_{L}=$ Line voltage

(2) $I_{p}=I_{L}$, where $I_{p}=$ Phase current, $I_{L}=$ Line current

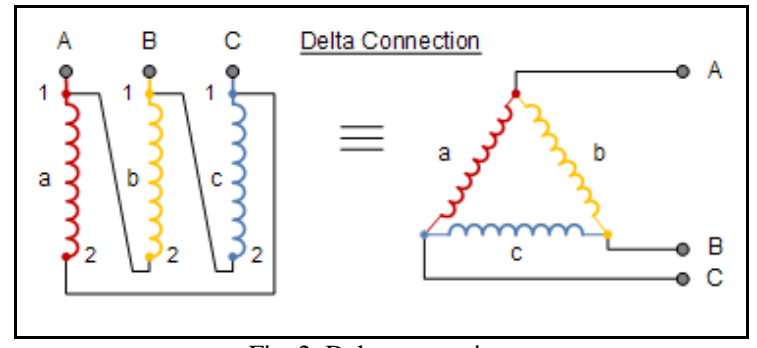

Fig. 2. Delta connection.

Useful equations:

(3) $V_{p}=\frac{V_{L}}{\sqrt{3}}$, where $V_{p}=$ Phase voltage, $V_{L}=$ Line voltage

(4) $I_{p}=I_{L}$, where $I_{p}=$ Phase current, $I_{L}=$ Line current

One of the most significant advantages of using bank of three single phase transformers is that, if one unit of the bank becomes out of order, then the bank can be run as open delta. To achieve a sinusoidal voltage in the secondary, there should be a third harmonic component in the magnetizing current of the transformer. The delta connection will provide a closed path for the circulation of the third harmonic component of the current. Delta connection is more economical for low voltage transformers. However, in delta-delta transformer connection, it is not suitable for three phase four wire system [7].

Using this trainer, the students will be able to learn how to connect transformer banking in delta-delta configuration without putting them at risk. The user will just push the button for delta-delta to configuration. Then, the students will do the wiring based on the correct configuration of delta-delta

\section{B. Transformer Delta and Delta Configuration}

In delta connection, as in Fig. 3, phase voltage is same as line voltage which results to a greater number of turns in the winding. But phase current is one divided by the square root of 3 times the line current. For this reason, the cross-section of the windings is very less. This makes the connection economical for low voltages transformers.

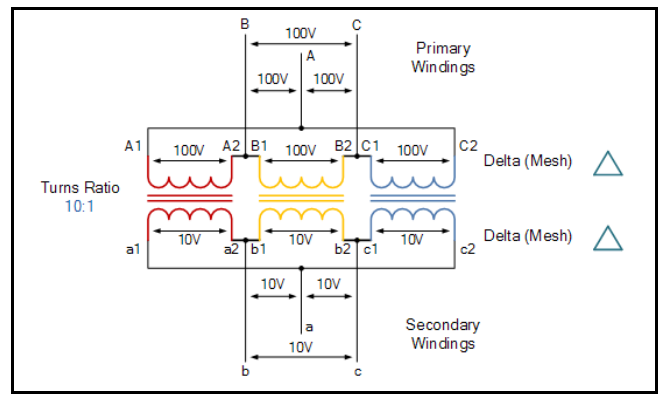

Fig. 3. Transformer delta-delta configuration.
Delta-delta configuration is suitable for large, low voltage transformers. This type of connection is not usual but is used for some industrial facilities to reduce the damages from single-to-line ground faults on the primary side.

\section{Transformer Star and Star Configuration}

Wye-wye (also known star-star) transformers, as shown in Fig. 4, can serve both three-phase and single-phase loads. The single-phase load should be distributed as evenly as possible between each of the three phases and neutral.

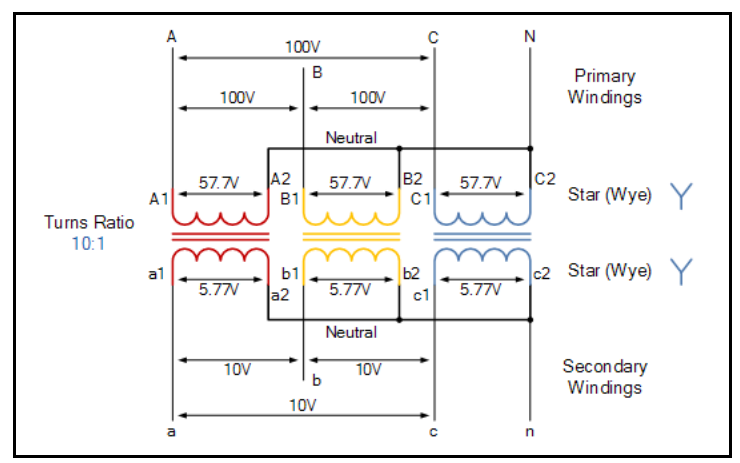

Fig. 4. Transformer wye- delta configuration.

Table I shows the summary of the relationship of voltage and current in different transformer banking configurations. Each equation is very important in determining the expected values in having the different connections in the logic trainer kit.

TABLE I: VOLTAGE AND CURRENT RELATIONSHIPS IN TRANSFORMER

\begin{tabular}{|l|c|c|}
\hline \multicolumn{2}{|c|}{ BANKING } \\
\hline Phase voltage & $V_{P}=V_{L} / \sqrt{3}$ & DELTA \\
\hline Line voltage & $V_{L}=V_{P} x \sqrt{3}$ & $\mathrm{~V}_{\mathrm{L}}=\mathrm{V}_{\mathrm{L}}$ \\
\hline Phase current & $\mathrm{I}_{\mathrm{P}}=\mathrm{I}_{\mathrm{L}}$ & $I_{P}=I_{L} / \sqrt{3}$ \\
\hline Line current & $\mathrm{I}_{\mathrm{P}}=\mathrm{I}_{\mathrm{L}}$ & $I_{L}=I_{P} x \sqrt{3}$ \\
\hline
\end{tabular}

Using low cost materials below, this trainer will be very flexible when it comes to improving the efficiency of the trainer with respect to the changing loads.

\section{Programmable Logic Controller (PLC)}

A programmable logic controller (plc) is an industrial computer control system that continuously monitors the state of input devices and makes decisions based upon a custom program to control the state of output devices [4].

Almost any production line, machine function, or process can be greatly enhanced using this type of control system. However, the biggest benefit of using a PLC is the ability to change and replicate the operation or process while collecting and communicating vital information.

Another advantage of a PLC system is that it is modular. That is, you can mix and match the types of Input and Output devices to best suit your application. Fig. 5 shows the Programmable Logic Controller (PLC) being used in this research project. Due to the limitation of the number of inputs and outputs of this device, there will be two PLCs in this design. 


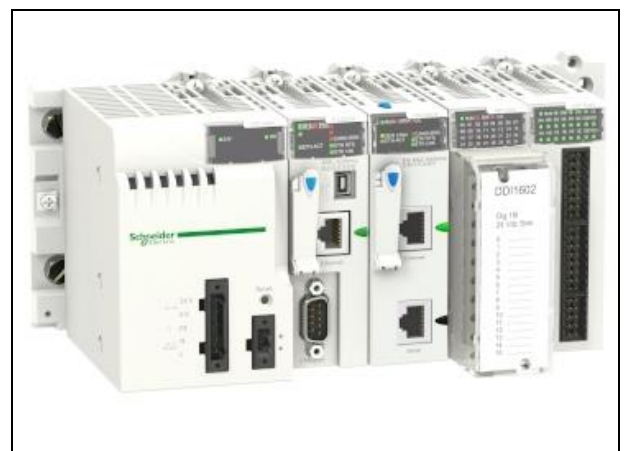

Fig. 5. Programmable logic controller used in the trainer.

\section{E. Logic Trainer Functionality}

Fig. 6 shows the overall flow of the system for the logic trainer. Basically, there will two plc's to be used in the design one for each transformer configuration. One plc will serve as delta configuration and the other one will be for star connection. The user will have to choose on what configuration for each PLC.

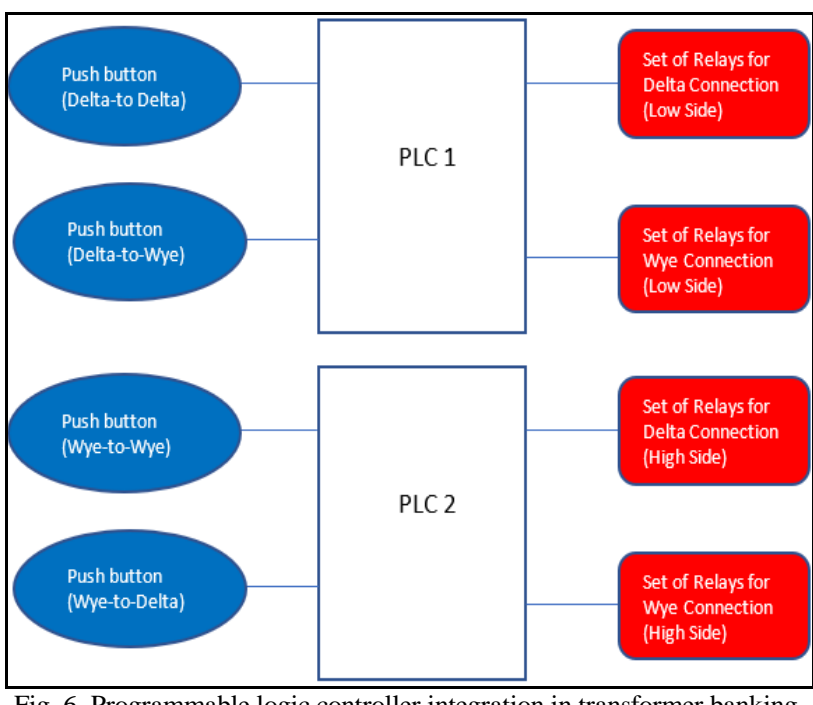

Since there are four possible combinations of the connection, this transformer banking trainer kit needs two PLCs to have a total of four banking connections. Since one PLC can only accommodate two banking configuration due to the limited number of pins for inputs and outputs, there will be two PLCs needed in the implementation of the trainer kit design.

\section{RESUlTS AND DISCUSSION}

The design presented in Fig. 7 is composed of three transformers recycled from used automatic voltage regulator (AVR). This low-cost design can be used efficiently in three phase system analysis.

The main highlight of this trainer is the integration of PLC. This trainer will enable the students to implement the various transformer banking configuration without manipulating the input three-phase AC voltage which is very dangerous. The slot for the transformer banking in the high and low side is just part of a 24-V DC supply to the input of the PLC in which the program inside the PLC will only work if it is being configured correctly by the students. The transformer banking was already pre-connected using the relays. If the PLC will recognize the correct configuration, then it will send an output that will energized the respective relays of the desired configuration. A reset button is provided for the students to refresh the PLC and enable the students to choose another type of banking configuration. And again, the students will re-configure according to the required connection, then push the button to command the PLC of what type of banking is to be perform.

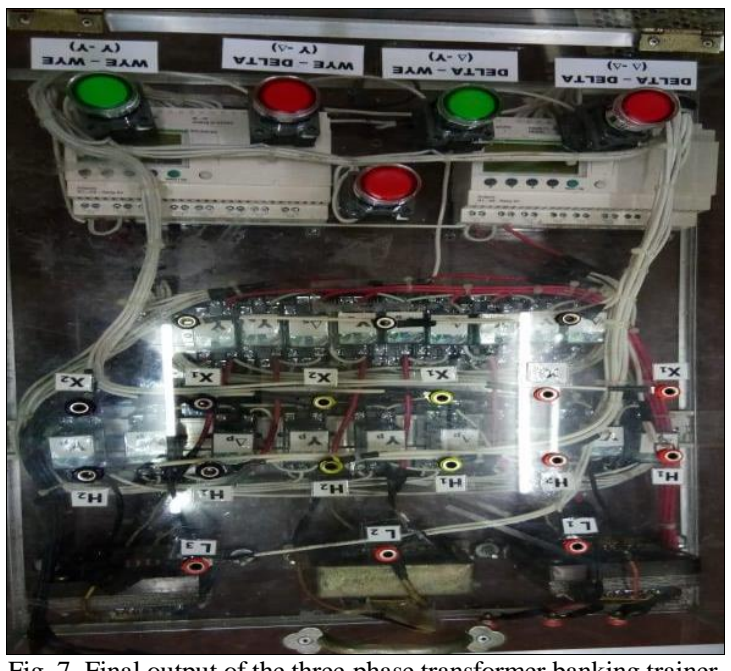

Fig. 7. Final output of the three-phase transformer banking trainer.

\section{A. Basic Operation}

The primary goal of this research project is to protect the personnel doing the experiments in three-phase transformer banking. In reality, transformers operates in high voltages which will be very dangerous to the students in doing their lab activities. Hence, some techniques or methods should be implemented to secure the safety of any personnel using the equipment. With the integration of PLC into the system, the different types of transformer banking will be appreciated and implemented without exposing to high voltages. Basically, the following steps will be observed in using the trainer:

1. Choose the type of transformer banking. The first thing to do is to choose what type of configuration to be used. The user will have to select the push button for the bankingdelta-delta, delta-wye, wye-wye, and wye to delta.

2. Wiring the system. After selecting the type of transformer banking, the next step is the wiring of the system based on the selected configuration. Basically, the students will be connecting the wires in such a way that they are doing an actual transformer configuration, say, delta-delta transformer banking.

3. Checking the connection. Successful wiring suggests that the system will function as it should be. Say, if the selected configuration was delta-delta, then there will be voltage and current that can measured at the output. However, if the proper connection was not executed correctly, then the trainer will not produce signal outputs. This was made possible by the embedded PLCs into the system. This is where the safety being introduced to the trainer kit. 


\section{B. Star-Star Transformer Configuration}

To have a star-star transformer banking configuration, one terminal of each phase of individual side should be connected. In Fig. 8, the common terminal is indicated with suffix 1 in both primary and secondary. In this case, voltages of primary and secondary are in same phase. This is the reason why this type of connection is called zero degree connection [5], [6].

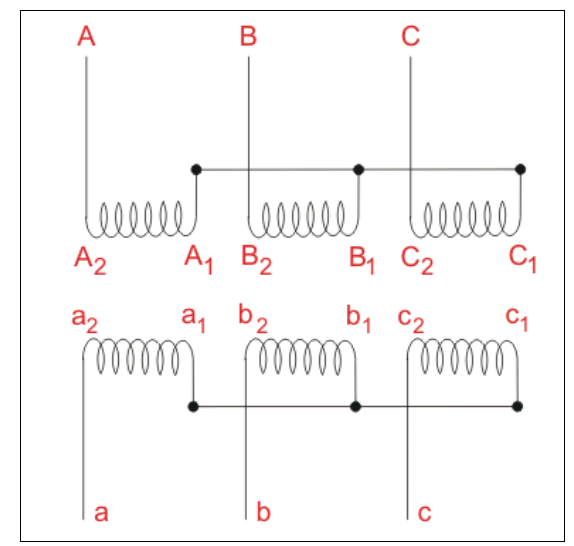

Fig. 8. Star-star three phase transformer connection.

\section{Delta-Delta Transformer Configuration}

In Fig. 9, to have a connection in delta-delta configuration, terminals with suffix 1 of each phase primary winding should be connected to terminal with suffix 2 of the next phase primary winding [7], [8].

In situations where the primary is high voltage side, then $\mathrm{A} 1$ will be connected to $\mathrm{B} 2$, then $\mathrm{b} 1$ to $\mathrm{C} 2$, and $\mathrm{C} 1$ to $\mathrm{A} 2$. This shows that similarly in the low voltage side, terminal with suffix 1 of each phase winding should be connected to terminal with suffix 2 of the next phase winding. Suggesting that a1 will be connected to b2, b1 to c2, and finally, c1 to be connected to a2 [5], [9].

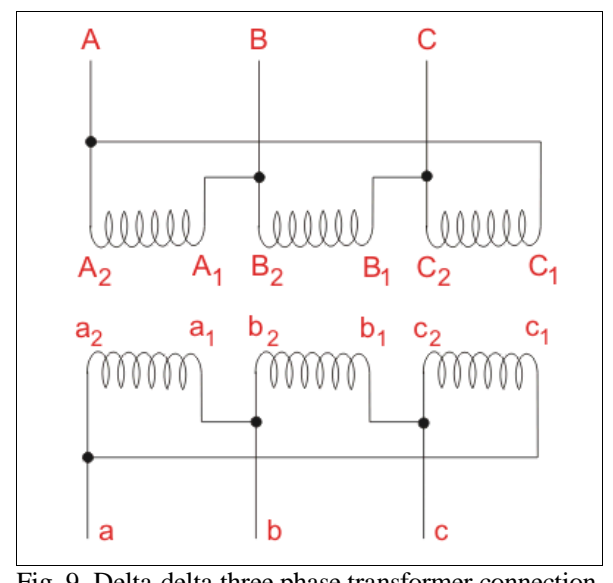

\section{Delta-Star Transformer Configuration}

Connecting delta-star transformer of three phase transformer is just similar to star-delta connection. One can just interchange the high voltage side and low voltage side of star-delta transformer in Fig. 10 then the configuration will become delta-star connected three-phase transformer. For simplicity, it suggests that small letter of star-delta connection will be replaced by capital letters and the small letters by capital letters in delta-star transformer connection
[5], [10], [11].

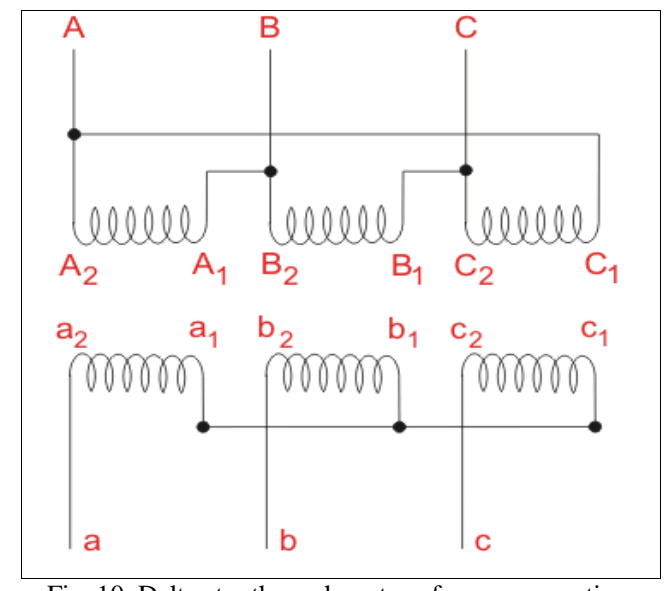

Fig. 10. Delta-star three phase transformer connection.

\section{CONCLUSION}

This research will bridge the gap between theoretical concepts of transformer banking and its actual operation with the help of programmable logic controller (PLC). In electrical engineering, the concept of transformers is very essential to the success of engineering students. Thus, learning the basic of transformers should be taught properly in universities. Programmable Logic Controller (PLC) is an industrial solid-state computer that monitors inputs and outputs and makes logic-based decisions for automated processes or machines. With the integration of PLC, the equipment and the user will be protected from incidents caused by electricity. Students will be able to learn on how to configure four (4) different types of transformer banking, namely, (a) delta-wye; (b) wye-delta; (c) delta-delta; and (d) wye-wye. The interconnection of the system made possible with the aid of relays. Also, the transformers being used in this research project were gathered from damaged computer's automatic voltage regulators. The trainer developed in this research will be a good equipment to fully grasp the concept of transformers and best way for the students to expand their knowledge towards electrical engineering.

\section{CONFLICT OF INTEREST}

The authors declare no conflict of interest.

\section{AUTHOR CONTRIBUTIONS}

This research would not be possible without the collaborative efforts of the researchers. Engr. Sanchez, Engr. Loreto, and Mr. Minoza worked together in conceptualizing the research. Engr. Sanchez focused on the flow of the system, Mr. Minoza designed the prototype, and Engr. Loreto worked mainly on the electronics portion of the design and the documentation of the research project.

\section{ACKNOWLEDGMENT}

The researchers would like to thank Caraga State University - Cabadbaran Campus for the support in terms of physical equipment and financial aspect for the entire project. 
Also, to the faculty members of Electrical Engineering of for valuable inputs on transformer banking and prototyping.

\section{REFERENCES}

[1] J. Olivares-Galván, P. Georgilakis, E. Vázquez-Martínez, and J. Mendieta-Antúnez, "Comparison of three-phase distribution transformer banks against three-phase distribution transformers," presented at 7th Mediterranean Conference and Exhibition on Power Generation, Transmission, Distribution and Energy Conversion (MedPower 2010), 2010.

[2] C. S. Siskind, Electrical Machines, Second edition, USA: International Student Edition.

[3] Three Phase Transformer Connections and Basics. (2018). [Online]. Available:

https://www.electronics-tutorials.ws/transformer/three-phase-transformer .html

[4] A. S. Rahama1 and D. Mahmoud, "Control of induction motors by using programmable logic controllers (PLC)," International Journal of Science and Research (IJSR), vol. 5, pp. 1923-1926, 2016.

[5] Three Phase Transformer Connections. [Online]. Available: http://www.electricaleasy.com/2014/05/three-phase-transformer-connect ions.html

[6] Electrical4U. (2019). Single Three Phase Transformer vs Bank of Three Single Phase Transformers. [Online]. Available: https://www.electrical4u.com/single-three-phase-transformer-vs-bank-of -three-single-phase-transformers/

[7] (2012). Using Single-Phase Transformers to Create 3-Phase Systems. [Online].

Available: http://www.ecmweb.com/basics/using-single-phase-transformers-create3-phase-systems

[8] A. E. Fitzgerald, C. Kingsley, and S. D. Umans, Electrical Machines, USA: McGraw-Hill, 1992, pp. 87-89.

[9] E. R. Laithwaite and L. L. Freris, Electric Energy: Its Generation, Transmission and Use, Great Britain: McGraw-Hill, 1980, pp. 35-41
[10] S. J. Chapman, Electrical Machines, USA: McGraw-Hill, 2005.

[11] J. B. Gibbs, Transformer Principles and Practice, USA: McGrawHill, 1950, pp. 6-11

Copyright $\odot 2019$ by the authors. This is an open access article distributed under the Creative Commons Attribution License which permits unrestricted use, distribution, and reproduction in any medium, provided the original work is properly cited (CC BY 4.0).

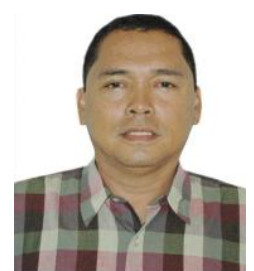

Anthony M. Minoza was born in Cabadbaran, Agusan del Norte, Philippines in 1963. He received the BS in electrical engineering in 1985 from University of Bohol, Philippines.

In 1988, he joined Northern Mindanao College of Arts, Science \& Technology, Philippines, as an educator, where he was a Mechanical Plant Operator from 1988 to 1992 , and has been a professor since 1992. His main research interests include renewable energy systems, power electronics, electrical layout designing, and smart-grid power distribution systems.

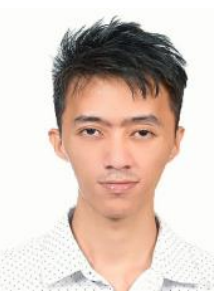

Jayson C. Loreto was born in Prosperidad, Agusan del Sur, Philippines in 1990. He received the BS in electronics engineering in 2013 and BS in electrical engineering in 2014 from Mindanao State University Iligan Institute of Technology, Philippines.

In 2017, he joined the Faculty of Electrical Engineering, Caraga State University - Cabadbaran Campus, where he has been a Lecturer since 2017. His main research interests include renewable energy systems, microelectronics, power electronics, reactive power control, harmonics, and smart-grid power distribution systems. 